\title{
Propagule dispersal of the SE Asian seagrasses Enhalus acoroides and Thalassia hemprichii
}

\author{
Cristina Day A. Lacap ${ }^{1,2}$, Jan E. Vermaat ${ }^{3, *}$, Rene N. Rollon ${ }^{1,2,3}$, Hildie M. Nacorda ${ }^{1,3}$ \\ ${ }^{1}$ The Marine Science Institute and ${ }^{2}$ Environmental Science Program, College of Science, University of the Philippines, \\ Diliman, Quezon City, The Philippines \\ ${ }^{3}$ Department of Environmental Science and Water Resources, International Institute for Infrastructural, \\ Hydraulic and Environmental Engineering, PO Box 3015, 2601 DA Delft, The Netherlands
}

\begin{abstract}
Dispersal rates of seeds and fruits of the 2 common SE Asian seagrasses Enhalus acoroides and Thalassia hemprichii were quantified under field conditions during flotation and the subsequent period of bottom dispersal. For E. acoroides, traveling speeds of buoyant seeds were timed for 70 different experimental batches of 10 to 30 propagules in seagrass beds across 9 different sites on the Bolinao reef flats, and during different seasons and tidal conditions. For T. hemprichii, only 3 experiments could be done due to the limited availability of propagules in this less frequently flowering species. Overall, fruits and seeds of E. acoroides floated at a speed of $0.26 \pm 0.02 \mathrm{~km} \mathrm{~h}^{-1}$ (mean \pm standard error), whereas those of $T$. hemprichii traveled at $0.47 \pm 0.15 \mathrm{~km} \mathrm{~h}^{-1}$. Median fruit and seed flotation times were 158 and 0.5 h, respectively, for E. acoroides, and 55 and <0.5 h, respectively, for T. hemprichii. Dispersal rates were similar to in situ measured flows due to tides and wind together. Neither the difference between species nor that between propagule types was significantly different, which is in agreement with their similar sinking velocities in still seawater but in contrast with a marked difference in seed volume and weight. Estimating the distance that could be covered by floating fruits led to medians of 41 and $23 \mathrm{~km}$ for E. acoroides and T. hemprichii, respectively, pointing to a considerable dispersal capacity of these propagules. Floating seeds traveled only a limited distance $(<5 \mathrm{~km}$ at most for E. acoroides and $<13 \mathrm{~km}$ for $T$. hemprichii). In situ bottom dispersal of $E$. acoroides seeds stopped after 2 to 5 d, i.e. after the germinating seedlings had formed a hairy mass at the base that anchored them to the sediment. Maximum distance traveled over the sediment by observed seeds was $204 \mathrm{~cm}$, and mean rates ranged between 10 and $29 \mathrm{~cm} \mathrm{~d}^{-1}$. In 2 of the 3 experiments, seeds of $T$. hemprichii moved much faster over the sediment (around $100 \mathrm{~cm} \mathrm{~d}^{-1}$ ) than those of $E$. acoroides, disappearing from the experimental tracks within 2 to $3 \mathrm{~d}$, probably largely due to herbivory or burial by invertebrates.
\end{abstract}

KEY WORDS: Dispersal · Buoyancy $\cdot$ Reproductive effort · Seagrass $\cdot$ SE Asia $\cdot$ Pollen $\cdot$ Seeds $\cdot$ Fruit Resale or republication not permitted without written consent of the publisher

\section{INTRODUCTION}

Seagrasses form and maintain dense meadows largely by clonal branching leading to new shoots (Tomlinson 1974, Vermaat et al. 1995, Vermaat \&

${ }^{*}$ Corresponding author. Present address: Institute for Environmental Studies, Vrije Universiteit, De Boelelaan 1087, 1081 HV Amsterdam, The Netherlands.

E-mail: jan.vermaat@ivm.vu.nl
Verhagen 1996, Marbà \& Duarte 1998), and sexual propagation and seedling establishment often contribute little to shoot recruitment. Notable exceptions are annual species or populations of Zostera, Halodule and Halophila spp. (Hootsmans et al. 1987, Inglis 2000), where seedling recruitment is the main source of the first generation of new shoots in a growing season.

Establishment of new populations in favorable but remote habitats probably occurs by sexual propagules. 
Dispersal ranges of seagrass propagules, however, are largely unknown. For Zostera marina, the dispersal range is limited to within a few tens of meters from the mother bed (Orth et al. 1994, Ruckelshaus 1996). Even for macro-algae like Sargassum sp., which has substantially smaller $(<200 \mu \mathrm{m})$ and lighter propagules than the seeds of most seagrass species, dispersal ranges are highly localized, with $98 \%$ settling within $1 \mathrm{~m}$ from the source plant (Kendrick \& Walker 1995). Probably, therefore, only very small fractions of seagrass propagule cohorts travel far and have a chance to realize remote colonization (Sauer 1988).

Naturally released seeds of Enhalus acoroides and Thalassia hemprichii have positive buoyancy for a limited period (Den Hartog 1970, Brouns \& Heijs 1986, Kuo et al. 1991), i.e. until the thin outer seed coat has withered. Also the fruits of both species remain afloat. When positively buoyant, seeds and fruits may travel floating on the water surface for some time. When the seeds have sunk, however, they may still be moved over the sediment by waves and currents, as well as by benthic fauna (e.g. brittle stars, alpheid shrimps, fish; pers. obs.), until they get trapped in depressions and anchor by rooting. In E. acoroides, an initial anchorage results from a mass of hyphen-like hairs that are formed soon after release and that attach to sediment grains (Brouns \& Heijs 1986). Seeds of both species have no dormancy, i.e. they germinate readily after release from the fruit (Den Hartog 1970, Brouns \& Heijs 1986, Kuo et al. 1991, Rollon 1998).
The present study assessed in situ propagule dispersal rates for 2 common SE Asian seagrasses, Enhalus acoroides and Thalassia hemprichii. Our aims were to establish (1) the duration of the positive buoyancy period, (2) dispersal rates, at both the water and the sediment surfaces, and (3) the time between arrival on the sediment surface and a more permanent anchorage by the first roots. The data will allow a verification of the dispersal pattern found for temperate Zostera marina (Orth et al. 1994, Ruckelshaus 1996) and can serve as an estimate of the modal distance that dispersing propagules can cover to colonize new habitat. Additionally, we report on water surface dispersal rates of pollen-bearing male flowerlets of E. acoroides to estimate the distance over which successful pollination may occur in this dioecious species. E. acoroides displays synchronous mass pollen release during afternoon low tides, and pollen life span is limited (Troll 1931, Den Hartog 1970, Rollon 1998).

\section{MATERIALS AND METHODS}

Seeds of Enhalus acoroides were carefully spread out over the water surface of a flow-through seawater tank in the Bolinao outdoor experimental facilities to estimate the duration of the positive buoyancy period. The remaining buoyant seeds were counted every 30 min until all seeds had sunk. This experiment was conducted with (1) seeds from carefully opened

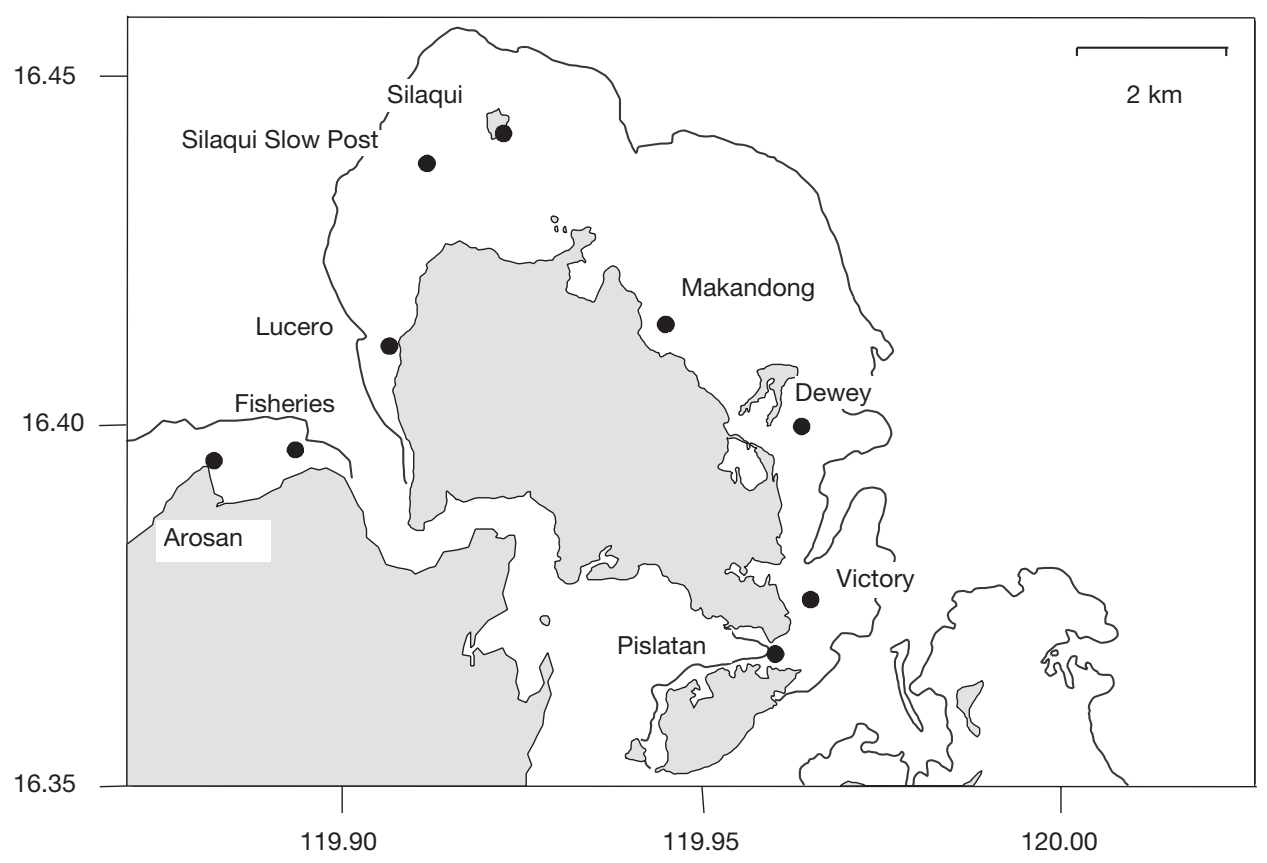

Fig. 1. Locations of the sites of the floating seed dispersal experiments on the Bolinao reef flat system. Gray areas are land, the drawn line indicates the reef slope 
mature fruits, and (2) seeds from fruits that had naturally opened and started to dehisce. Seed volumes and weights were quantified for several batches of each species to estimate volume-specific weight. Fall velocities of batches of 50 seeds of both species were timed in a $1000 \mathrm{ml}$ graduated cylinder containing seawater.

Water surface dispersal rates were assessed in situ for seeds and fruits (both species) as well as male flowerlets (Enhalus acoroides) on several occasions during the year (June 12 to 16, 1999; November 9 to 10, 1999; July 25, 2000; November 28 to 30, 2000; December 4 to 6, 2000 ) and on different reef flat sites around Bolinao (Arnedo, Lucero, Silaqui Slow Post, Silaqui, Makandong, Pislatan, Arosan, Victory, Dewey, and off the Fisheries School; Fig. 1), in an attempt to cover existing temporal and spatial variation in flow environments. Ebb as well as flood conditions were sampled during each campaign, whereas the November/December 2000 campaigns covered a spring/neap cycle. In each individual in situ experiment, 10 to 20 propagules were released on the water surface and allowed to travel a pre-measured distance, which was timed with a stopwatch. Availability of Thalassia hemprichii fruits and seeds was limited; therefore, we have fewer data on this species. Monsoon- and tide-related flow directions and rates were obtained from Rivera (1997, unpubl.).

Bottom dispersal experiments were carried out in a shallow dense mixed seagrass bed with small open gaps at Arnedo. We demarcated a $2 \times 2 \mathrm{~m}$ 'runway' or track with sticks at $50 \mathrm{~cm}$ intervals and placed a batch of 15 to 30 non-floating seeds at the center. On subsequent days, we traced the position of individual seeds with a $50 \times 50 \mathrm{~cm}$ stainless steel quadrat that had a $10 \mathrm{~cm}$ grid. We then expanded the grid to cover an area of $4 \times 5 \mathrm{~m}$ and, finally, carefully inspected the immediate surroundings of our experimental runways. This experiment was performed with Thalassia hemprichii in June and November 1999, and with Enhalus acoroides in June 1999 and March 2000.

Table 1. Seed characteristics (means \pm SE) of Enhalus acoroides and Thalassia hemprichii. Data were collected in March and November 1999. Replication was 51 and 62, respectively

\begin{tabular}{|lccc|}
\hline & $\begin{array}{c}\text { Enhalus } \\
\text { acoroides }\end{array}$ & $\begin{array}{c}\text { Thalassia } \\
\text { hemprichii }\end{array}$ & $\begin{array}{c}\mathrm{p} \\
(t \text {-test })\end{array}$ \\
\hline $\begin{array}{l}\text { Seed dry weight } \\
(\mathrm{mg})\end{array}$ & $249 \pm 1$ & $102 \pm 6$ & $<0.001$ \\
$\begin{array}{l}\text { Seed volume (ml) } \\
\begin{array}{l}\text { Volume-specific } \\
\text { dry weight }\left(\mathrm{mg} \mathrm{ml}^{-1}\right)\end{array}\end{array}$ & $0.90 \pm 0.01$ & $0.26 \pm 0.01$ & $<0.001$ \\
$\begin{array}{l}\text { Fall velocity in still } \\
\text { seawater }\left(\mathrm{cm} \mathrm{s}^{-1}\right)\end{array}$ & $10.0 \pm 0.1$ & $10.0 \pm 0.2$ & 1.000 \\
\hline
\end{tabular}
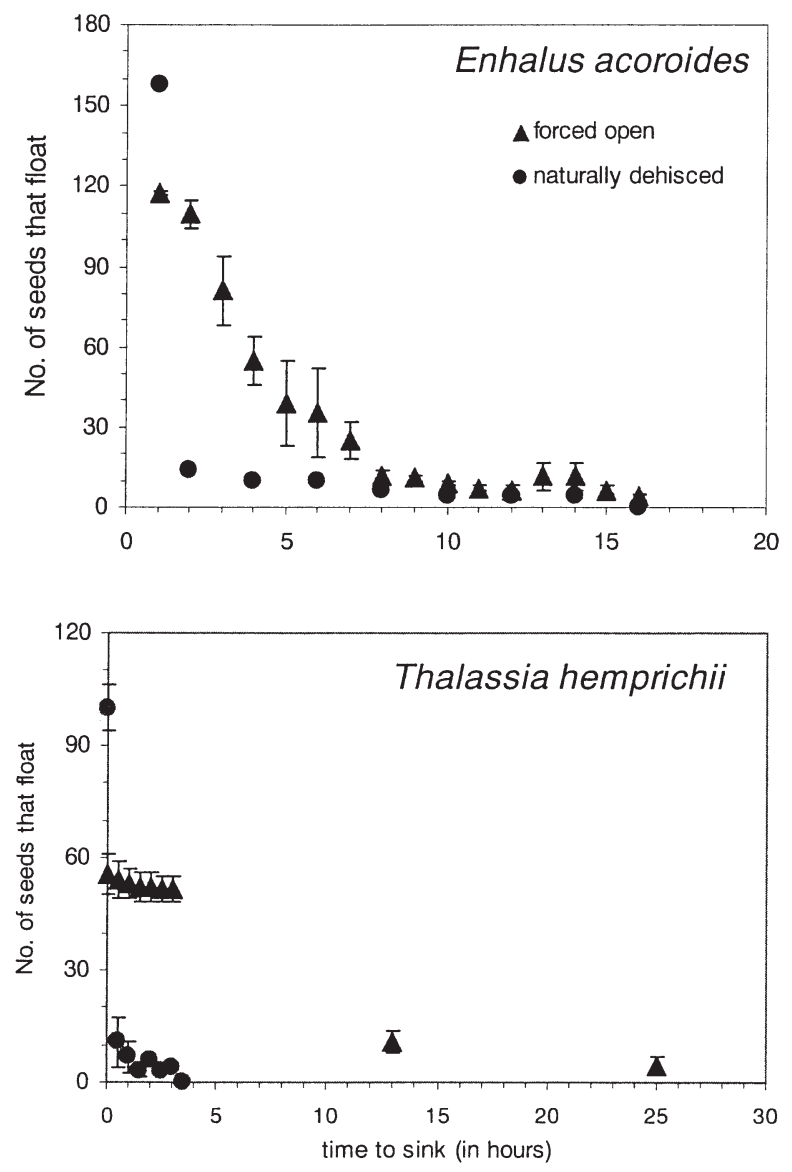

Fig. 2. Flotation curves of Enhalus acoroides (upper panel) and Thalassia hemprichii (lower panel) seeds that were either naturally dehisced or obtained from carefully opened almost mature fruits. For E. acoroides, median flotation times were 3 and $0.5 \mathrm{~h}$ for the forced open and naturally dehisced seeds, respectively. The maxima were 14 and $15 \mathrm{~h}$, respectively. For T. hemprichii, these numbers were 8.5, 0.3, 25 and $35 \mathrm{~h}$, respectively

\section{RESULTS}

Naturally released seeds of Enhalus acoroides and Thalassia hemprichii floated only briefly and for substantially shorter time than seeds from artificially opened fruits (Fig. 2): the observed maximum flotation time for a naturally released seed was $14 \mathrm{~h}$ for $E$. acoroides and $3.5 \mathrm{~h}$ for $T$. hemprichii in flow-through water. Apparently mature fruits open up and sink in less than 1 to $11 \mathrm{~d}$ after dislodgement (Fig. 3). Seeds of E. acoroides were much larger than those of T. hemprichii, but specific weights of the latter were higher (Table 1). This contrast did not result in a significant difference in sinking time (Table 1).

Floating dispersal of Enhalus acoroides propagules was affected by season (faster in the windy NE monsoon season of November and December) as well as by 


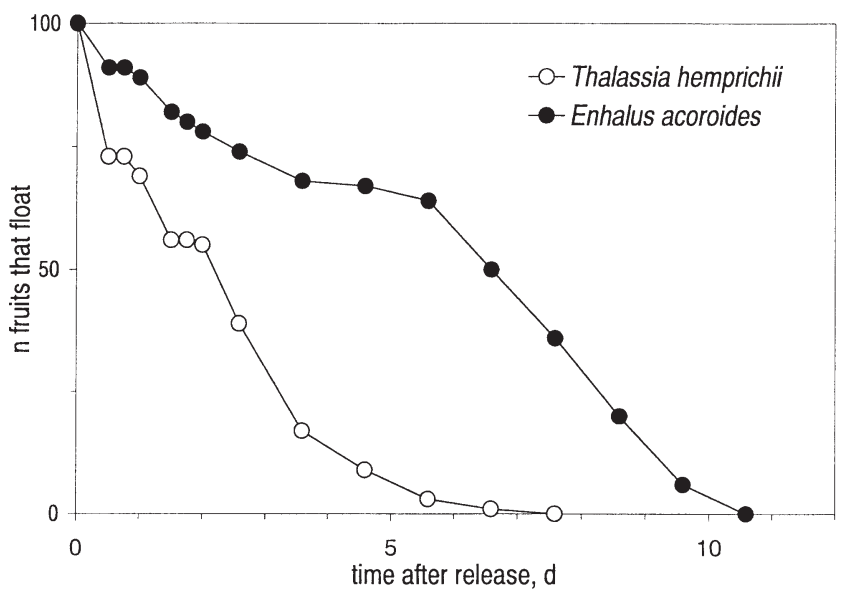

Fig. 3. Flotation curves of mature fruits of Enhalus acoroides and Thalassia hemprichii. Median flotation times were 158 and $55 \mathrm{~h}$ and maxima were 245 and 173, respectively

site, and the latter factor explained a substantial part of the variance (Table 2). No significant differences were observed between seeds and fruits of the same species or among seeds or fruits of the 2 species (Table 3). Male flowerlets of $E$. acoroides traveled significantly faster than seeds or fruits (Tables $2 \& 3$ ).

Wind- and tide-induced currents are in the range of $<10 \mathrm{~cm} \mathrm{~s}^{-1}$ (Rivera 1997, unpubl.) during the calm wind conditions also observed during the flotation experiments. Our observed dispersal rates were in the same range; hence, seeds and fruits probably float as passive drogues with the water. Dispersal distances were estimated as the product of mean traveling speeds (Table 3) and the duration of the flotation period (Figs. 2 \& 3). Floating seeds covered only limited distances $(<5 \mathrm{~km}$, Table 3$)$, but fruits of both species had a considerably higher capacity for long-distance dis-

Table 2. Three-way ANOVA of Enhalus acoroides propagule dispersal rates at the water surface as a function of propagule type (fruits, seeds, male flowerlets), site (9 sites around Bolinao) and season (wet SW monsoon of June and July versus dry NE season of November and December). Interactions were suppressed. The proportion of the variance explained (\%var) is derived as SS factor/SS total

\begin{tabular}{|lrcc|}
\hline Factor & \%var & df & $\mathrm{p}$ \\
\hline Propagule type $^{\mathrm{a}}$ & 5 & 2 & 0.003 \\
Site & 30 & 8 & 0.001 \\
Season & 5 & 1 & 0.001 \\
Error & 60 & 130 & \\
Total & 100 & 141 & \\
aMale flowerlets dispersed at a significantly higher rates \\
than fruits and seeds, but the latter 2 were not signifi- \\
cantly different; see also Table 3
\end{tabular}

Table 3. Dispersal speed of and distance traveled by in situ floating propagules of Enhalus acoroides and Thalassia hemprichii. Dispersal speed data pooled over experiments are presented as means $\pm \mathrm{SE}$ (number of individual experiments). Distance traveled is estimated from mean dispersal speed and median or maximum flotation periods from Figs. 2 \& 3 . Observed traveling speeds were converted to $\mathrm{km} \mathrm{h}^{-1}$, see 'Materials and methods'; distance traveled is in $\mathrm{km}$

\begin{tabular}{|c|c|c|}
\hline $\begin{array}{l}\text { Species } \\
\text { Propagule type }\end{array}$ & Speed $^{\mathrm{a}}$ & $\begin{array}{l}\text { Distance traveled } \\
\text { (median; maximum) }\end{array}$ \\
\hline
\end{tabular}

\section{Enhalus acoroides}

$\begin{array}{lcc}\text { Fruit } & 0.26 \pm 0.02(70) & 40.9 ; 63.5 \\ \text { Seed } & 0.27 \pm 0.02(69) & 0.1 ; 3.7 \\ \text { Male flowerlets } & 0.54 \pm 0.13(3) & -\end{array}$

Male flowerlets $\quad 0.54 \pm 0.13(3)$

\section{Thalassia hemprichii}

$\begin{array}{lcc}\text { Fruit } & 0.43 \pm 0.16(3) & 23.4 ; 73.5 \\ \text { Seed } & 0.52 \pm 0.15(3) & -\end{array}$

${ }^{a}$ Within species, the speeds of fruits and seeds were not significantly different (paired $t$-test, $\mathrm{p}=0.52$ ). Between species, both fruits and seeds did not differ significantly $(\mathrm{p}=0.30$ and $\mathrm{p}=0.10$, respectively)

persal: medians ranged between 20 and $40 \mathrm{~km}$, whereas maxima ranged up to 60 to $70 \mathrm{~km}$ under calm flow conditions (Table 3).

Movement of Enhalus acoroides seeds on the sediment surface declined substantially within 2 to $4 \mathrm{~d}$, in parallel with the formation of the hairy mass at the base. The distance covered in this first period differed substantially between the 2 experiments (Fig. 4), probably due to a much stronger wind-induced flow over the north-facing experimental site exposed to the full NE monsoon in March. Mean traveling speeds were 10 and $29 \mathrm{~cm} \mathrm{~d}^{-1}$ in these first periods before settlement, with maxima of 77 to $170 \mathrm{~cm} \mathrm{~d}^{-1}$. Seeds of Thalassia hemprichii traveled faster (around $100 \mathrm{~cm} \mathrm{~d}^{-1}$;

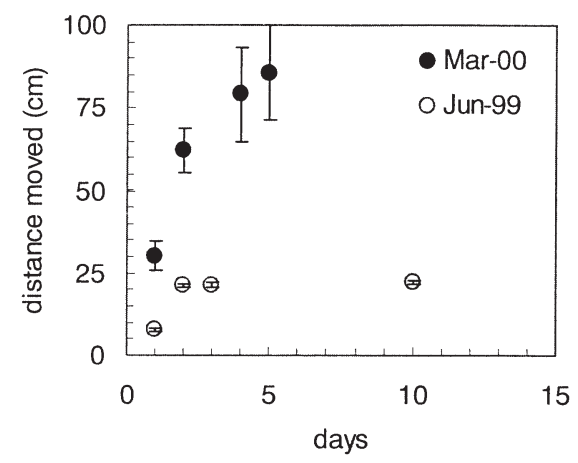

Fig. 4. Bottom dispersal experiments with Enhalus acoroides seeds: mean distance moved ( $\pm 1 \mathrm{SE}$ ). After 2 to $4 \mathrm{~d}$, the seeds had initiated germination and formed hyphen-like hairs at the base. Mean dispersal rates during the first $2 \mathrm{~d}$ were $10.4 \pm$ 0.5 and $28.9 \pm 4.1 \mathrm{~cm} \mathrm{~d}^{-1}$ for June and March, respectively. Ultimate maximal displacements were 30 and $204 \mathrm{~cm}$ in 10 and $5 \mathrm{~d}$ 
Table 4. In situ bottom dispersal rates of seeds of Thalassia hemprichii (means $\pm \mathrm{SE}$; maximum [n seeds]) measured during 3 experiments in June and November 1999. Seeds could be traced back only during the first 1 or $2 \mathrm{~d}$

\begin{tabular}{|ll|}
\hline Dates & Speed $\left(\mathrm{cm} \mathrm{h}^{-1}\right)$ \\
\hline June 12 to 13 & $4.0 \pm 0.4 ; 7.7(19)$ \\
June 14 to 16 & $0.4 \pm 0.1 ; 1.0(16)$ \\
November 9 to 11 & $4.8 \pm 0.4 ; 10.3(14)$ \\
\hline
\end{tabular}

Table 4) in 2 of the 3 experiments, but the rate was similar to that of E. acoroides in 1 of the 2 June experiments. These seeds were generally lost within $2 \mathrm{~d}$ of the experiment, either because they moved beyond the runway perimeter or, more likely, because they were collected by benthic invertebrates. We observed alpheid shrimps, their symbiotic gobies and ophiuroid brittlestars manipulating our experimental seeds. In 2 small experiments, we offered batches of 6 and $8 E$. acoroides seeds to alpheid shrimps and their gobies. In both cases, all seeds were collected by both animals and brought into the shrimp's burrow within minutes.

\section{DISCUSSION}

We estimated that naturally released seeds of Enhalus acoroides have a short period of positive buoyancy (at most $14 \mathrm{~h}$ ) during which they can travel an estimated distance of $3.7 \mathrm{~km}$ with the flowing water (applying the mean rate from Table 3), which is about a third of the longitudinal axis of the Bolinao reef flat system (Fig. 1). Although we could not quantify it, the period of positive buoyancy of Thalassia hemprichii seeds is probably even shorter (Fig. 2), and hence the distances traveled are probably similar or less. Seed dimensions (volume, weight, specific weight) were markedly different, but this did not lead to a difference in sinking velocity after loss of their buoyancy.

Dislodged fruits of both species are positively buoyant, and almost mature fruits still travel for considerable time before the seeds are shed. A median estimate would be $2 \mathrm{~d}$ for Thalassia hemprichii and $7 \mathrm{~d}$ for Enhalus acoroides (Fig. 3). With a calm flow commonly occurring in reef-sheltered lagoons, the fruits of $E$. acoroides and $T$. hemprichii can cover distances of 41 and $23 \mathrm{~km}$, respectively (Table 3). These dispersal ranges are substantial and surpass the length axes of the Bolinao reef system during both NE and SW monsoon seasons. Due to the prevailing flow patterns, however, dispersal over the Bolinao reefs is generally unidirectional, i.e. southward during the NE monsoon (November to April) and southeastward during the SW monsoon (May to October; Rivera 1997). Maturing fruits of T. hemprichii are easily dislodged (anatomic evidence in Kuo et al. 1991) and the same probably holds for E. acoroides. We therefore conclude that fruits must be important long-distance dispersal propagules, although we lack data on the incidence of fruit dislodgment in the field. Still, we speculate that since typhoons are frequent and predictable over annual time scales in most of SE Asia (Davies 1980), these may be the main vehicle for longer-distance fruit dispersal across larger seas. Typhoons generate strong currents easily surpassing $50 \mathrm{~cm} \mathrm{~s}^{-1}\left(1.8 \mathrm{~km} \mathrm{~h}^{-1}\right.$; Rivera 1997). Combining these with maximum flotation periods of fruits leads to an estimate of the maximum dispersal range of fruits in the order of 400 and $300 \mathrm{~km}$ for E. acoroides and T. hemprichii, respectively.

Further dispersal of Enhalus acoroides probably continues for 2 to $5 \mathrm{~d}$ after buoyancy is lost, i.e. until the anchoring hairy mass is formed. The mean distance traveled over the sediment differed greatly between experiments, but the maximum distance moved by a seed was $204 \mathrm{~cm}$ (Fig. 3). Bottom dispersal of Thalassia hemprichii seeds was faster and probably continued for a longer period, since we lost the seeds rapidly from our runway, and since both Kuo et al. (1991) and we collected seeds and fruits from shores adjacent to $T$. hemprichii stands (pers. obs., Bolinao, The Philippines and Nha Trang, Vietnam). Therefore, we have no wellestablished upper bound of the distance covered by bottom-dispersing seeds of this species under a calm sea but conservatively estimate it at less than $100 \mathrm{~m}$.

Compared to the published findings for temperate Zostera marina (Orth et al. 1994, Ruckelshaus 1996), our dispersal ranges over the bottom are of similar magnitude (i.e. in the order of meters). However, our estimated dispersal ranges during flotation (several tens of kilometers) are much larger. This suggests that long-distance dispersal by floating fruits is important, particularly when dislodgment of maturing fruits is a frequent phenomenon. For the latter frequency we unfortunately have no quantitative estimates; therefore, we do not speculate and estimate the frequency of such long-distance dispersal over potentially hundreds of kilometers.

Floating male flowerlets of Enhalus acoroides carrying pollen disperse at the water surface with a mean velocity around $13 \mathrm{~km} \mathrm{~d}^{-1}$, which would lead to an estimate of a modal distance of 5 to $7 \mathrm{~km}$ covered during an afternoon low-tide event. This would allow pollen exchange between flowering stands across considerable parts of the Bolinao reef flat (Fig. 1), particularly since pollen release appears synchronous (Troll 1931, Den Hartog 1970, Rollon 1998). We conclude for $E$. acoroides that genetic exchange by pollen dispersal may occur over spatial scales in the order of kilometers $(<10 \mathrm{~km})$, which is several orders beyond the scale of 
meters reported for underwater pollinating Zostera marina (Ruckelshaus 1996). Effective pollen exchange through frequent dispersal and pollination over these scales may explain the genetic similarity between populations of E. acoroides across the Bolinao reef system (K. Araño unpubl., C. Billot et al. unpubl.).

Acknowledgements. This work was funded by the INCODEV program of the European Commission (project ERBIC18CT980292). We thank our partners in the project for useful discussions. Cristopher Ragos and Jack Rengel are acknowledged for skillful assistance in the field and Mike Fortes of MSI for around-the-clock hospitality in his Bolinao laboratory. Karen Araño, Erik de Ruyter, Joop Ouborg, Claire Billot, Filipe Alberto, Ester Serrao and Carlos Duarte are thanked for the discussions on the population genetics of Philippine seagrasses.

\section{LITERATURE CITED}

Brouns JJWM, Heijs FML (1986) Production and biomass of the seagrass Enhalus acoroides (L.f.) Royle and its epiphytes. Aquat Bot 25:21-45

Davies JL (1980) Geographical variation in coastal development, 2nd edn. Longman, London

Den Hartog C (1970) The seagrasses of the world. North Holland Publishers, Amsterdam

Hootsmans MJM, Vermaat JE, Van Vierssen W (1987) Seedbank development, germination and early seedling survival of two seagrass species from The Netherlands: Zostera marina L. and Zostera noltii Hornem. Aquat Bot 28:275-285

Inglis GJ (2000) Disturbance-related heterogeneity in the seed banks of a marine angiosperm. J Ecol 88:88-99

Kendrick GA, Walker DI (1995) Dispersal of propagules of

Editorial responsibility: Otto Kinne (Editor),

Oldendorf/Luhe, Germany
Sargassum spp. (Sargassaceae: Phaeophyta): observations of local patterns and consequences for recruitment and population structure. J Exp Mar Biol Ecol 192:273-288

Kuo J, Coles RG, Long WJL, Mellors JE (1991) Fruits and seeds of Thalassia hemprichii (Hydrocharitaceae) from Queensland, Australia. Aquat Bot 40:165-173

Marbà N, Duarte CM (1998) Rhizome elongation and seagrass clonal growth. Mar Ecol Prog Ser 174:269-280

Orth RJ, Luckenbach M, Moore K (1994) Seed dispersal in a marine macrophyte: implications for colonization and restoration. Ecology 75:1927-1938

Rivera PC (1997) Hydrodynamics, sediment transport and light extinction off Cape Bolinao, Philippines. PhD thesis, IHE-Delft and Wageningen Agricultural University

Rollon RN (1998) Spatial variation and seasonality in growth and reproduction of Enhalus acoroides (L.F.) Royle populations in the coastal waters off Cape Bolinao, NW Philipines. PhD thesis, IHE-Delft and Wageningen Agricultural University

Ruckelshaus MH (1996) Estimation of genetic neighborhood parameters from pollen and seed dispersal in the marine angiosperm Zostera marina L. Evolution 50:856-864

Sauer JD (1988) Plant migration, the dynamics of geographic patterning in seed plant species. University of California Press, Berkeley

Tomlinson PB (1974) Vegetative morphology and meristem dependence: the foundation of productivity in seagrasses. Aquaculture 4:107-130

Troll W (1931) Botanische Mitteilungen aus den Tropen. II Zur Morphologie und Biologie von Enhalus acoroides (Lin f.) Rich. Flora 125:427-456

Vermaat JE, Verhagen FCA (1996) Seasonal variation in the intertidal seagrass Zostera noltii Hornem.: coupling demographic and physiological patterns. Aquat Bot 52:259-281

Vermaat JE, Fortes MD, Agawin NR, Duarte CM, Marbà N, Uri JS (1995) Meadow maintenance, growth and productivity in a mixed Philippine seagrass bed. Mar Ecol Prog Ser 124:215-255

Submitted: October 5, 2001; Accepted: February 26, 2002 Proofs received from author(s): May 14, 2002 